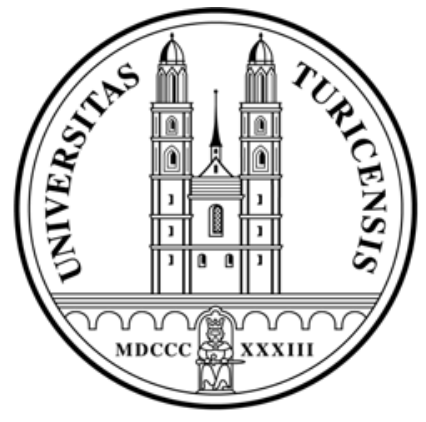

Institute for Empirical Research in Economics

University of Zurich

Working Paper Series

ISSN 1424-0459

Working Paper No. 367

The Value of a Statistical Injury:

New Evidence from the Swiss Labor Market.

Andreas Kuhn and Oliver Ruf

April 2008 


\title{
The Value of a Statistical Injury: New Evidence from the Swiss Labor Market.
}

\author{
Andreas Kuhn, University of Zurich*† \\ Oliver Ruf, University of Zurich
}

March 2008

\begin{abstract}
This paper deals with the compensation for non-fatal accident risk in Switzerland and presents empirical estimates of the value of a statistical injury. We approach the problem of endogenous sorting of workers into jobs with different accident risks based on unobserved productivity differences twofold. First, we have access to the number of accidents not only at the level of industries, but within cells defined over industry $\times$ skill-level of the job, which allows us to estimate risk compensation within groups of workers defined over the same cells. Second, we capitalize on the partial panel structure of our data which allows us to empirically isolate the wage component specific to the employer. Our different approaches to identification in fact yield very different estimates of the value of a statistical injury. Our preferred estimate gives an estimate of about 40,000 Swiss francs (per prevented injury per year).
\end{abstract}

JEL classification: J31, J17

Keywords: Compensating Wage Differentials, Value of a Statistical Injury, Risk Measurement, Unobserved Productivity

\footnotetext{
* Olivier Steiger, Rainer Winkelmann and Josef Zweimüller provided many helpful comments and suggestions which significantly improved this study. We thank Alois Fässler from the Swiss Accident Insurance Fund (Suva) for providing us with the data and helpful guidelines concerning the data. We also thank Simon Büchi for reviewing parts of the code for the empirical analysis. Simone Gaillard and Jonathan Lorand proof-read the manuscript. Financial support by the Swiss National Science Foundation under grant no. 100012-103970 (Oliver Ruf) and by the research grant of the University of Zurich under grant no. 53211602 (Andreas Kuhn) are gratefully acknowledged.

${ }^{\dagger}$ Institute for Empirical Research in Economics, Bluemlisalpstrasse 10, CH-8006 Zurich, Switzerland, phone: +41 (0)44634 36 07, kuhn@iew.uzh.ch.

${ }^{\ddagger}$ Institute for Empirical Research in Economics, Bluemlisalpstrasse 10, CH-8006 Zurich, Switzerland, phone: +41(0)44634 37 10, oliruf@iew.uzh.ch.
} 


\section{Introduction}

It has long been recognized in economics that differences in wages are not only due to the fact that individuals differ in their productivity-relevant characteristics (e.g. education), but also due to the fact that the jobs offered to workers differ enormously along various dimensions (workplace safety being only one important example). Workers presumably not only value the monetary payoff from working, but also the non-monetary characteristics, potentially giving rise to compensating wage differentials (Rosen, 1986). This means firms offering jobs with "negative" characteristics, that is, attributes to which workers attach a negative value, must attract workers by paying them higher wages ceteris paribus, thus "compensating" them for the negative aspects of the job (and vice versa for "positive" workplace characteristics). Nonmonetary characteristics of jobs are of course manifold, most empirical studies though focus on workplace safety, that is on the risk compensation for both fatal and non-fatal accidents (e.g. Viscusi and Aldy, 2003).

The theory of compensating wage differentials has inspired a huge number of empirical studies trying to pin down the compensation for undesirable workplace attributes. Due to the implicit trade-off between job amenities and wages, observed (or rather, estimated) compensating wage differentials can be used to assess the value of a statistical life or injury, respectively. These empirical results in turn may directly influence public policy, since cost-benefit analyses with respect to safety regulations need empirical assessments on the monetary value of such regulations (this applies not only to regulations of safety at the workplace, but also to environmental regulations for example).

Yet, the intuitive appeal of the theory notwithstanding, empirical studies face some fundamental problems concerning the identification of compensating wage differentials. The main problem is rooted in unobserved productivity differences between individuals and the thereupon based sorting of workers into jobs with different risks (due to the positive income elasticity of the value of a statistical accident). This presumably explains the rather large variation in the estimated compensation for risks on the one hand, but also the fact that many empirical studies report no compensation for risk or even report compensating wage differentials having the "wrong" sign (at least with respect to non-fatal injury risks). For example, the survey by Viscusi and Aldy (2003) reports a rather wide range of estimates for the value of a statistical injury from about $\$ 20,000$ to $\$ 70,000$ (for the United States only).

This chapter presents empirical evidence on the compensation for non-fatal accident risk in Switzerland, using a data set compiled from two different sources (which we will discuss in detail below). Our study has three main features. First, we will exclusively focus on non-fatal accidents. This focus reflects the fact that most accidents have (fortunately) nonfatal consequences and thus, from the viewpoint of public health and safety, merit the most attention. $^{1}$ In the year 2004 (the year of our empirical analysis), for example, the Swiss Accident Insurance Fund reports about 246,000 non-fatal accidents related to work but only

\footnotetext{
${ }^{1}$ Our focus though is also due to the available data on non-fatal accidents as well as the empirical approach we take, as we will discuss in detail in section 3 and section 4 below.
} 
188 fatal accidents. Second, we observe the number of non-fatal accidents not only within entire industries, but also within cells defined by industry $\times$ skill-level of the job. This is a tremendous advantage from an empirical point of view, since risks at (too) high levels of aggregation mix the risks of very different groups of workers and different willingness to pay for avoiding risk, which might lead to biased estimation of the compensation for risk in the workplace. Third, we capitalize on the availability of longitudinal wage information, which allows us to use simple panel estimation methods in order to isolate the firm wage component. We believe that our empirical approach, on the one hand using the number of non-fatal accidents within narrower cells than usually available, and on the other hand combining panel data estimation methods with simple non-parametric stratification, transcends the typical hedonic wage function approach often used in the literature on the subject.

The main findings of our empirical analysis are the following. First, we find that a simple hedonic wage regression, where the observed log wage is regressed on the risk measure (and additional control variables) yields a compensation for non-fatal accident risk which is statistically zero, a result that is in line with some previous empirical studies. The leading explanation for this result (which runs counter to theory) is presumably the sorting of workers which differ in their unobserved productivity. Second, moving on to, in a sense, more sophisticated (but, we believe, in this case also more reliable) methods, we find a positive point estimate for the compensation of non-fatal accident risk. Our preferred point estimate yields an implicit value of a statistical injury of about 40,000 Swiss francs (which lies well within the range given by studies from the U.S. labor market, as well as from studies outside the U.S.). On the other hand, using different estimation methods yields considerably different values for the value of a statistical injury. As we will discuss later, a significant cause of this wide range of estimates is the difference in the estimation methods used. Third, comparing the different estimation methods may shed some light on the problem of endogenous sorting of workers into jobs with different risks, which presumably yields biased estimates for the compensation of risk. Our results are in fact in line with the argument supported by Hwang et al. (1992), among others, that such endogenous sorting gives rise to severe underestimation of risk compensation. Fourth, we find significant differences between men and women on the one hand, and between smaller and larger firms on the other hand with respect to the compensation of non-fatal accident risk. Fifth and finally, our results also show that the kind of risk-data available can make an important difference for the empirical assessment of risk compensation.

The rest of this paper is organized as follows. We start with a discussion of the relevant literature on compensating wage differentials, focusing on empirical studies estimating the compensation for non-fatal accident risk. In section 3, we discuss the two data sources we rely on, discuss the construction of the variables of main interest - along with some descriptive statistics. We then expore issues of identification and estimation in section 4. Specifically, we will discuss three different approaches to identification and estimation. We start with a simple hedonic wage regression model, where the wage is simply regressed on individual- and firm-specific characteristics. The second approach is based on the idea that we can control 
for unobserved heterogeneity of individuals by appropriately stratifying the sample. The third approach we take capitalizes on the longitudinal structure of the wage data. We isolate the wage component, which is specific to the firm and then use only this part of the wage to estimate risk compensation. The results of the different estimation methods are presented and discussed in section 4. Based on our econometric results, we further present estimates of the value of a statistical (non-fatal) accident in Switzerland. Section 6 concludes.

\section{$2 \quad$ Related Literature}

There is a large number of empirical studies which try to pin down the compensation for accident risks, as well as for a wide range of other job amenities and disamenities (the surveys by Viscusi and Aldy (2003) and Viscusi (1993) are of special interest here; see also the more recent, but less thorough survey by Ashenfelter (2006)). ${ }^{2}$ Most empirical studies find a positive compensation for fatal accident risk, often yielding high implicit values of a statistical life. For example, Viscusi and Aldy (2003) report that half of the studies from the U.S. labor market surveyed in their article give a value of a statistical life within the range of $\$ 3.8-\$ 9.0$ million (in 2000 dollars), the median estimate being about $\$ 7$ million. Most studies from outside the U.S. labor market give estimates within the same range. It is difficult to assess the exact reasons for this wide range of estimates, since the studies differ in various ways, for example with respect to the available data and risk measure ${ }^{3}$, or in the econometric methods applied. The evidence on the compensation for non-fatal accident risk is much less coherent, which is somewhat surprising since most studies that present estimates of such compensation are based on the same data as estimates for the compensation for fatal accident risk. Viscusi and Aldy (2003) report, for both the U.S. as well as other labor markets, a probable range for the value of a statistical injury of about $\$ 20,000-\$ 70,000$ per injury.

The main problem from the empirical point of view is the potential sorting of workers into jobs differing in their risk of accidents. Hwang et al. (1992), among others, argue that the problem of main concern are differences in unobservables which in turn relate to the productivity of workers and thus may lead to sorting of workers into jobs with different risks. The sorting of workers in turn is endogenous due to the fact that the income elasticity of the value of a statistical life or injury is positive, i.e. more productive workers sort themselves into less risky jobs by accepting ceteris paribus lower wages. Viscusi and Aldy (2003), for example, report an income elasticity of about 0.5-0.6. On the other hand though, Shogren and Stamland (2002) argue that the bias in estimating the compensating wage differential could

\footnotetext{
${ }^{2}$ Compensating wage differentials have also been found, for example, for the risk of unemployment (Lalive et al., 2006; Moretti, 2000), for shift work (Kostiuk, 1990), and uncertainty with respect to future earnings (Feinberg, 1981).

${ }^{3}$ Most importantly perhaps, some studies rely not on direct measures of risk (i.e. number of accidents), but base their analyses on tradeoffs outside the labor market, e.g. on the tradeoff between traffic accidents and the price of automobiles (Dreyfus and Viscusi, 1995) or fatalities related to bicycle accidents and the prize of bicycle helmets (Jenkins et al., 2001). Other studies have used subjective assessments of risk, as for example Viscusi and O'Connor (1984) and Viscusi and Hersch (2001).
} 
run in the other direction, assuming that workers not only differ in their productivity, but also with respect to their skill in avoiding accidents. Thus, workers in risky jobs could be either more tolerant to risk or more skilled in avoiding risk (or both). Thus they show that the estimated risk compensation might actually be upward biased, rather than downward biased. Some studies have tried to approach the problem of endogenous sorting by using instrumental variables (DeLeire and Levy, 2004; Garen, 1988, for example,). The study by Garen (1988), for example, tries to correct for the endogeneity of job risk by using a system of simultaneous equations where marital status and the number of dependents are used as instruments for the preference over risk.

Another empirical issue concerns the measurement of the risk of an accident. First, as pointed out by Mellow and Sider (1983) for example, typical survey data are more often than not plagued by measurement error, i.e. it seems to be the case that workers often misreport their industry affiliation and/or their exact occupation. Assuming that this kind of measurement error is random, this causes the compensating differential to be biased towards zero. Second, there clearly is a trade-off of the following form. On the one hand, risk measurements at a low level of aggregation are preferred, as otherwise one might mix workers with very different occupations into the same risk categories. On the other hand though, risk measures at a low aggregation level run into the problem that many cells will have zero risk, at least for shorter periods of time. This is specifically true for fatal accident risk, yet obviously also applies to non-fatal injuries.

The most prevalent approach in the empirical literature is via estimation of hedonic wage functions, that is, by running regressions of the wage on characteristics of both the workers and jobs. As we will make explicit in section 4, this approach is likely to fail identification because it is unlikely that this approach can effectively deal with the problem of endogenous sorting of workers into jobs (as pointed out above, some studies have tried to instrument endogenous sorting by using family characteristics). As we will discuss in detail in section 4 below, our empirical approach of choice relies on the panel structure of the wage data. Thus, our study also relates to work on matched employer-employee data (e.g. Abowd and Kramarz, 1999) as well as the panel data estimation methods in general (e.g. Wooldridge, 2002). We cannot directly apply the methods of Abowd and Kramarz (1999) though, because our wage data has a longitudinal structure only with respect to the employer, but not with respect to the individual worker.

To the best of our knowledge, there is only a single published study on the compensation of accident risk for Switzerland by Baranzini and Ferro-Luzzi (2001), focusing on fatal accident risk only. They report estimates for the value of a statistical life ranging from about 12 to about 32 million Swiss francs. Besides having a different focus (our focus in on non-fatal accident risk only), our study differs in at least two further ways. First, we have access to the number of non-fatal accidents not only within industries, but within narrower cells, defined over industry $\times$ skill-level of the job. Second, we do not primarily and exclusively rely on simple hedonic wage regressions for the estimation of risk compensation, instead we use 
the longitudinal structure of the wage information in a first stage in order to deal with the endogenous sorting of workers.

\section{Data}

\subsection{Data Sources}

We use two different data sources. The first data source is the Swiss Wage Structure Survey (SWSS; "Lohnstrukturerhebung (LSE)"), which is a biannual survey among firms which is administered and made available by the Swiss Federal Statistical Office. The SWSS is one of the two largest official surveys in Switzerland focused mainly on employment-relevant information. ${ }^{4}$ The SWSS is a survey of firms, covering the population of large firms along with a random sample of small firms. We use three different waves of the SWSS (from the years 2000, 2002, and 2004) and we extract individual monthly earnings along with several individual-specific characteristics (see section 3.4 below) on details.

Our risk measure corresponds to the number of non-fatal accidents within cells defined over industry (forty different industries on a two-digit level) and skill-level of the job (four different levels). The data have been provided by the Swiss Accident Insurance Fund (SAIF; "Schweizerische Unfallversicherungsanstalt (Suva)"), which is the most important accident insurance fund in Switzerland. The number of non-fatal accidents within industry $\times$ skill-level cells are available for the year 2004 .

\subsection{Definitions}

One of the main features of our analysis is that our risk measure $r_{k}$ gives the number of non-fatal accidents per year and per 1,000 workers within a given industry $\times$ skill-level cell $k$ (instead of within-industry only). Data on the absolute number of non-fatal accidents for the year 2004 is available within cells defined over industry $\times$ skill-level of job. Now, because the SAIF does not directly have the number of workers within these cells and because workers are not uniformly distributed over these cells, we also need to know the distribution of workers over these cells in order to compute the risk of a non-fatal accident. To this end, we simply use the distribution of workers in the SWSS (from the year 2004), and then approximate the population distribution of workers by multiplying the number of workers within a given cell with the total number of workers which are covered by the SAIF (about 1.827 millions in the year 2004).

Note that there is a fundamental trade-off with respect to the risk measure chosen: On the one hand, risk measures on a highly disaggregated level are preferred, such that we do

\footnotetext{
${ }^{4}$ The second important labor market survey is the Swiss Labor Force Survey (SLFS; "Schweizerische Arbeitskräfteerhebung (SAKE)"). The two main advantages of using the SWSS over the SLFS are the following: First, the SWSS allows isolating the wage firm fixed effect, which is the part of the observed wage where risk compensation should show up. Second, the SWSS is (opposed to the SLFS) mailed to employers, and thus misclassification of occupations and industries should only be of minimal order (the same is arguably true for wages).
} 
not pool accident risks of individuals working in very different occupations and jobs. This has been pointed at, for example, by Viscusi (1993, p.1928), noting that "[t]he main deficiency of industry-based data is that they pertain to industry-wide averages and do not distinguish among the different jobs within that industry [...]". On the other hand, accidents observed at a very low level of aggregation also give rise to estimation problems, because the number of accidents tends towards zero for most cells if we shrink the size of the risk-relevant cells. That, in fact, is the reason why we decided not to use the information about fatal accidents for this study. Disaggregating the number of fatal accidents over the skill-level of job actually yields far too many cells with zero number of accidents.

The SWSS includes average gross monthly wages for full-time employment (i.e. 172 hours per month), including mandatory social security contributions and extra pay (e.g. for night work, 13. monthly wage). The SWSS also includes several socio-demographic characteristics (e.g. age, gender, tenure, educational attainment (highest degree), citizenship), but also different firm characteristics (most importantly, the size of the firm along with the geographic location).

\subsection{Measurement Error}

One main advantage of our data is that measurement error in the risk data and industryaffiliation of workers is arguably of minor significance (as already mentioned in section 2, Mellow and Sider (1983) have pointed out the problem of misclassification of both industry and occupation). This is important because measurement error in the risk variable tends to bias the compensating wage differential towards zero (measurement error in the dependent variable (i.e. wage) is, of course, also common but of less concern). We are confident that the measurement error for both our risk measure and industry-affiliation is of no great importance, since the SWSS does not involve employees but obtains the data from the employer directly (such that misclassification of either industry and/or occupation is unlikely to occur). For the same reason, we also believe that our wage information is more reliable than the information available in typical survey data (although presumably less reliable than administrative data). Additionally, our risk measure is directly obtained from administrative sources and should thus cover all relevant accidents.

\subsection{Descriptive Statistics}

Table 1 shows descriptive statistics for both the overall sample as well as the sample of individuals in jobs of the lowest skill-level (that will be used in the empirical analysis discussed below). In both samples, we only consider workers aged between 16 and 64 (for men) and between 16 and 61 (for women). A second restriction applies to the size of the employer. Because we are estimating wage fixed effects for each firm, we also restrict the sample to workers from firms which have at least ten workers in each of the four job skill-levels in each year. The overall sample includes more than one million individual workers, the subsample of workers in the lowest skill-level (with respect to the job, not with respect to the educational attainment of 
the worker) consists of about 300,000 individual workers. In both cases, there are about 3,500 different firms (due to the restriction on firms). As we will discuss in-depth in section 4 below, our preferred estimation approach will focus exclusively on workers within a given skill-level as collected in the SWSS, as we believe that such a stratification of the workers yields more reliable estimates of the compensating wage differential.

We begin with describing the overall sample, which is representative of the Swiss labor market as a whole. The typical worker in the Swiss labor market has gross earnings equal to 6,300 Swiss francs a month, is about 40 years old and has about 9.5 years of tenure and is more likely to be a man. The average employer has more than 2,800 workers (reflecting the sampling structure of the SWSS as well as the restriction with respect to the selection of the employers). About two thirds of the workers are married, the other third single. The distribution of workers with respect to educational attainment highlights two important characteristics of the Swiss labor market in terms of education. First, compared to other countries, the number of workers with tertiary education is rather low (e.g. only about $5.5 \%$ of the workers have a university degree). Second, about half of the workers hold a vocational training. Another important characteristic of the Swiss labor market is the large fraction (about 20\%) of workers without Swiss citizenship.

Table 1 about here

Focusing on individuals working in jobs with the lowest skill-level (columns 3 and 4 of table 1) yields the expected result that some groups are overrepresented in the analysis sample relative to the overall sample of individuals (although this subset of individuals is similar to the overall sample with respect to some characteristics, for example age and size or the geographic location of the employer). ${ }^{5}$ Here, average monthly earnings are only about $70 \%$ of the overall average earnings (about 4,500 Swiss francs). Moreover, a worker from skilllevel four is more likely to be a woman, more likely to be married and much more likely not to have Swiss citizenship, compared with a worker from the overall sample. The most striking difference between the overall sample and the lowest skill-level sample though is the distribution of workers with respect to educational attainment. As table 1 shows, there are practically no workers with an educational degree above vocational training. This, in fact, is a desired result with respect to the empirical approach we take (see section 4 below): Given that education (of course not exclusively) reflects differences in productivity, focusing on workers with similar educational attainment also implies that these workers are more similar with respect to unobserved productivity-relevant characteristics (compared to workers from all job skill-levels). We believe that the variance of unobserved productivity is presumably lowest within the group of workers in the lowest skill-level (although this presumption obviously is fundamentally empirically untestable).

\footnotetext{
${ }^{5}$ The distribution of workers over the skill-level of jobs looks as follows: About $6 \%$ work in the highest level, about $20 \%$ in the second-highest level. $46 \%$ work in skill-level 3 , and the remaining $28 \%$ of the workers are in jobs of lowest skill-level.
} 
As table 1 also shows, the typical worker in the year 2004 was faced with the risk of a nonfatal, work-related accident of about $8.8 \%$ ( 88 accidents on average per 1,000 workers). In the sample of workers with lowest skill-level, the average risk was about half (about 43 accidents per 1,000 workers). Figure 1 shows a simple scatterplot between the average logarithmic monthly wage and the number of non-fatal accidents for workers from the lowest skill-level jobs at the level of industry $\times$ skill-level. The scatterplot shows no relation whatsoever between the two variables (if anything, the correlation goes the "wrong" way), which is underlined by the estimated slope coefficient from a regression of the average log earnings on the number of accidents - yielding essentially a zero point estimate, both in economic and statistical terms ( $\mathrm{t}$-value is approximately zero).

Figure 1 about here

This result is not especially surprising though since average wages within industries clearly may not only reflect differences with respect to accident risks, but also differences in the composition of workers and jobs. We thus now move on to issues of identification and econometric estimation.

\section{Identification and Estimation}

We now discuss issues of identification and estimation of the compensating wage differential for (non-fatal) accident risk. We start with a simple hedonic wage regression of the following form:

$$
y_{i j k}=\alpha+x_{i}^{\prime} \beta+z_{j}^{\prime} \gamma+\delta r_{k}+u_{i j k}
$$

Where $y_{i j k}$ is the natural logarithm of the gross monthly wage of individual $i$, working in firm $j$ and industry $\times$ skill-level cell $k . x$ is a (column) vector of individual characteristics including citizenship, educational attainment, age (and its square), tenure (and its square), a genderdummy and marital status. $z$ is a (column) vector of characteristics describing the firm (and thus reflecting the characteristics of the job), and includes the size of the firm (and its square) and the geographical location of the firm. $r$ is our risk measure, corresponding to the number of non-fatal accidents in industry $\times$ skill-level cell $k$ per 1,000 workers in the year 2004. $u_{i j k}$ is the unobserved error term, upon which identification of the compensating wage differential obviously critically hinges.

$\alpha, \beta, \gamma$ and $\delta$ are parameters to be estimated from the sample data at hand. The constant term $\alpha$ is, of course, of no special interest but simply serves the purpose of scaling the expected value of the error term to zero. The two parameter vectors $\beta$ and $\gamma$ are also, for the purpose of our analysis, of no particular interest. The parameter of main interest is $\delta$, which, under appropriate assumptions, corresponds to the compensating wage differential for non-fatal accident risk.

As explained in section 3, the number of non-fatal accidents is only available for a single 
point in time, so that we can essentially only run a cross-sectional hedonic wage regression ${ }^{6}$ (but we do have a partial panel structure with respect to wages, which we will try to capitalize on later; see section 4.4 below).

\subsection{Unobserved Heterogeneity and Worker Sorting}

Parameter $\delta$ (as are the other parameters) is identified if we are willing to assume that:

$$
\mathbb{E}(u \mid x, z, r)=\mathbb{E}(u)
$$

This means, if we can safely assume that the error term $u_{i j k}$ is mean independent of $(x, z, r)$, then all the parameters of the regression given by equation (1) are identified. However, as has been pointed out by several authors (e.g. Hwang et al., 1992) and discussed in section 2, there is good reason to act on the assumption that there is unobserved individual heterogeneity related to wages (that is, these differences somehow reflect differences in productivity not taken into account for by observed variables) and that "safety" is a normal good (i.e. the demand for "safety" increases as income rises). Thus, workers of high productivity sort themselves into less risky jobs by accepting lower wages ceteris paribus. To stick with the model from equation (1), the hedonic wage regression with unobserved individual heterogeneity made explicit can be written as:

$$
y_{i j k}=\alpha+x_{i}^{\prime} \beta+z_{j}^{\prime} \gamma+\delta r_{k}+\theta_{i}+\epsilon_{i j k}
$$

where $\left(\theta_{i}+\epsilon_{i j k}\right)$ corresponds to the error term $u_{i j k}$ in equation (1) whereby now we make the problem of individual heterogeneity explicit (for simplicity, $\theta$ is rescaled such that the partial of effect of $\theta$ on $y$ is equal to 1$).{ }^{7}$ Now, even if we can assume that $\epsilon_{i j k}$ is mean independent of $(x, z, r)$, identification of the compensating wage differential $\delta$ is only achieved if the unobserved effect $\theta$ is also mean independent of $(x, z, r)$. Whenever there is reason to believe otherwise, parameter $\delta$ is not identified (and neither are the other parameters identified, but that is of minor importance for our purposes, since we are not per se interested in these parameters).

As discussed in section 2, the leading reason for a correlation between $\theta$ and the accident risk $r$ is that $\theta$ reflects unobserved productivity, which is obviously related to the wage $y$. If the demand for safety actually increases with income and if we are, at the same time, unable to adequately control for productivity differences, then this could quite plausibly lead to a correlation between $\theta$ and $r$. That is, more productive workers (i.e. workers with aboveaverage $\theta$ ) sort themselves into less-risky jobs by accepting lower wages, which in turn leads

\footnotetext{
${ }^{6}$ Many, if not most, other empirical studies face the same problem of not observing the relevant risk measure over time, as pointed out by Hwang et al.: "While studies of this sort [i.e. panel studies] represent improvements over standard cross-sectional studies, their applicability is restricted by the availability of longitudinal data sets that include the relevant nonwage job attribute variables. In most cases, this is a binding constraint." (Hwang et al., 1992, p. 836).

${ }^{7}$ Note that the error term $\epsilon_{i j k}$ potentially also includes unobserved heterogeneity with respect to the firm. We will take up this issue in section 4.4 below.
} 
to a correlation between the productivity measure $\theta$ and the risk measure $r$, meaning that identification of the risk compensation parameter $\delta$ must ultimately fail.

In the following, we will discuss three different empirical approaches in turn, all of which are intended to mitigate the worker-sorting leading to biased estimates of the compensation for risk.

\subsection{Control Function}

The first approach, which we might label control-function approach, is to basically stick with the hedonic wage regression, but to try to control for as many observable characteristics (both at the individual and the firm/job level) as possible. In fact, controlling for the appropriate set of observed variables might entail identification of $\delta$, depending on which variables are observed, and thus can be controlled for in the regression model. Under 'typical' circumstances however, this approach is prone to fail identification, since the data sources usually available do not include enough control variables or the critical control variables, respectively. Nonetheless, we will also estimate hedonic wage regressions, mainly for reasons of comparison. We stress here that we would not place much confidence in the resulting estimates for the parameter $\delta$. The bottom line is that this approach to identification crucially hinges on the availability of enough control variables (describing both the workers and the jobs).

\subsection{Sample Stratification}

A second related approach is to stratify the sample in such a way as to minimize the variation in the unobserved error component $\theta$ (see equation (3)). That is, we run the very same hedonic wage regression as given by equation (1), but only on a narrow subset of individuals. Ideally, this subset consists of individuals presumably as similar as possible with respect to $\theta$. That is, stratification is the simple non-parametric counterpart of the control function approach. However, since most often it is very difficult to control for $\theta$, we think that stratifying the sample is probably a more fruitful approach.

Our stratification variable of primary interest is the skill-level of the job, which is recorded in the SWSS. Let $s_{i j} \in\{1,2,3,4\}$ be the skill-level of individual $i$ working in job $j$, where $s=1(s=4)$ corresponds to the highest (lowest) skill-level of a given job. We thus run the same hedonic wage regression as in equation (1), but only on a subset of individuals within a given skill-level $s$. Specifically, we will run the following regressions:

$$
y_{i j k}=\alpha+x_{i}^{\prime} \beta+z_{j}^{\prime} \gamma+\delta r_{k}+u_{i j k} \quad s_{i j} \geq s \in\{1,2,3,4\}
$$

Note that this approach to estimation is basically the same as the control function approach, the main difference being that stratification allows all parameter estimates to vary between different subsets of the sample ${ }^{8}$. However, we think it plausible that the main advantage of

\footnotetext{
${ }^{8}$ That is, the control function approach yields the same estimates as sample stratification if all parameters would be interacted with the variable on which stratification is based on. However, such a fully interacted
} 
the stratification is that we can minimize variation in $\theta$ in this way, which ideally renders a consistent estimate of the compensating wage differential $\delta .^{9}$

\subsection{Wage Decomposition and Firm Wage-Component}

Our third approach to identification and estimation is based on quite another idea, which tries to capitalize on the availability of panel data (with respect to the firm). ${ }^{10}$ Still, we can use the additional source of variation in wages stemming from the fact that the SWSS has a longitudinal structure (at least with respect to the firm) such that we can apply simple panel data methods (see, for example, Wooldridge, 2002).

To start with, let us assume that the observed natural logarithm of the wage $y_{i t}$ of individual $i$ in a given year $t$ can (conceptually) be decomposed in a linear model as follows:

$$
y_{i j t}=\lambda_{t}+\phi_{i}+\psi_{j}+\epsilon_{i j t}
$$

Abstracting from the time fixed-effect $\lambda_{t}$, equation (5) states that individual $i$ 's wage is the sum of an individual wage fixed-effect $\phi_{i}$, a firm wage fixed-effect $\psi_{j}$, and a remaining random error component $\epsilon_{i j t}$. The critical assumptions in this simple linear fixed effects model are the assumptions about the time invariance of both the individual and the firm fixed effect. However, since we are using panel data spanning only a short time period we believe that these assumptions are innocuous for our application - nonetheless allowing us to resort to the power of panel data methods. Importantly, note that the theory of compensating wage differentials essentially makes statements about the wage component specific to the employer (i.e. $\psi_{j}$ ), but not to the individual-specific part nor the random part of the wage.

This simple representation of the wage essentially states that the wage of a specific individual $i$ in a given year $t$ is the sum of an aggregate time effect (e.g. aggregate shocks), an individual-specific component (which is assumed to be time-invariant), a firm-specific part (also assumed to be time-invariant) and a random error term (varying over time, firms, and individuals). If it is possible to consistently estimate the wage firm fixed effect $\psi_{j}$ from the available data, we can essentially get rid of individual heterogeneity by simply running a hedonic wage regressing using the estimated wage firm-fixed effect $\hat{\psi}_{j}$ instead of the observed wage $y_{i j t}$ on our risk measure $r$, although we can not directly control for unobserved individual heterogeneity in the hedonic wage regression (because, remember, the risk measure is

regression model is, due to the large number of parameters to be estimated, often difficult to interpret.

${ }^{9}$ As we will show later, our stratification approach actually reduces the differences between groups of workers with respect to the observed wage (on this point, see table 5). For example, in the overall sample the difference in mean monthly earnings between men and women amounts to about 1,700 Swiss francs (about one third relative to the female average). In the subsample of workers within the lowest skill-level, the difference in average earnings amounts to only about 630 Swiss francs (relative to the female average, a bit less than 15\%). Although this is only suggestive evidence, we still believe that this exactly what one would expect if the presumption holds that the variance in $\theta$ is lower in the lower skill-levels of jobs.

${ }^{10}$ Of course, we could capitalize on repeated individual observations using for example the techniques proposed by Abowd and Kramarz (1999), but as explained in section 3, we only have temporal information about the employer but not the individual workers. 
not observed over time and because there is no person-identifier in the SWSS).

Thus, in a first stage, we run a simple regression model using the three consecutive waves of the SWSS:

$$
y_{i j t}=\alpha+x_{i t}^{\prime} \beta+z_{j t}^{\prime} \gamma+\lambda_{t}+\psi_{j}+u_{i j t} \quad \text { with } \quad s_{i j}=4
$$

Here, again, $x$ and $z$ are vectors of observed individual and firm characteristics and the parameter $\lambda_{t}$ captures aggregate wage shifts over time. The vector $x$ of observed individual characteristics is important here because we essentially use $x$ to proxy for otherwise unobserved individual heterogeneity. Moreover, we run this regression on a subset of individuals working in jobs with the lowest skill-level only, such that we can further dampen the problem of unobserved heterogeneity.

The regression model given by equation (6) is only of interest here because it allows us to estimate the firm wage fixed effects, represented by the vector $\psi_{j}$. Practically, $\psi_{j}$ is estimated from the data by including a separate dummy variable for each firm in the sample.

In the second stage, we run a regression very similar to the hedonic model from equation (1):

$$
\hat{\psi}_{i j k}=\alpha+x_{i}^{\prime} \beta+z_{j}^{\prime} \gamma+r_{k} \delta+u_{i j k} \quad \text { with } \quad s_{i j}=4
$$

where now the dependent variable is the estimated firm wage fixed effect $\hat{\psi}_{i j k}$ of individual $i$ working in firm $j$. Note that the unit of observation is still the individual worker, although the firm fixed effect obviously does not vary between individuals working in the same firm. This procedure, though, directly applies the right weighting scheme. Again, $r_{k}$ is the non-fatal risk measure in industry $\times$ skill-level cell $k$. Note that we still have to include both vector $x$ and $z$, because the estimated wage firm fixed effect $\hat{\psi}$ is not independent of $x$ and $z$. The main point is that the estimated wage firm fixed effect $\hat{\psi}$ should have been separated from the unobserved individual-specific component $\theta$.

\section{$5 \quad$ Econometric Results}

We now present the econometric results, starting with some simple hedonic wage regressions. We then go to discuss the results from stratifying the sample by skill-level, which yields results in the expected direction. Next, we present results from our preferred approach, regressing firm wage fixed-effects instead of individual wage on accident risk. Finally, we present empirical estimates for the statistical value of a injury (i.e. a non-fatal accident related to workplace activities), which are implicitly given by the estimates of the different econometric models.

\subsection{Hedonic Wage Regression}

Estimated parameters of the hedonic wage function, as given by equation (1), are given in table 2 (column 1). The point estimate of the non-fatal accident risk is negative $(-0.00005)$, 
although statistically not different from zero ( $\mathrm{t}$-value of about less than one in absolute value). This result is in fact in line with either endogenous sorting of workers. Note also that the other regressors have the expected sign.

Table 2 about here

As discussed in section 4, the leading explanation for the "wrong" sign of the risk variable is endogenous sorting of workers into jobs with different risks. As we do not put much confidence in this simple hedonic wage regression, so we quickly move on to the next results.

\subsection{Sample Stratification}

Columns 2 to 4 in table 2 also show parameter estimates from a simple hedonic wage regression, but only for a subset of workers each. As we narrow the range of the skill-level, the point estimate of risk compensation moves towards the expected direction. Focusing on workers in the lowest skill-level only yields a positive point estimate on the risk measure (0.00024), which moreover is almost statistically significant on the $10 \%$ level ( $t$-value of 1.63 ). The decrease in the $\mathrm{R}$-squared of the model reflects the fact that the stratification of the sample absorbs a large part of the variation in the regressors (e.g. educational attainment; see section 3), which otherwise explain a significant part of the variation in wages.

\subsection{Wage Firm Fixed Effects}

The last column in table A.1 in the chapter appendix shows the estimated firm wage fixedeffect by industry (at the two-digit level, only for the lowest skill-level of jobs). As shown in figure 2, a simple scatterplot of the average firm wage fixed-effect (averaged within industries) versus the number of non-fatal accidents now shows a clear positive relation between the two variables (as opposed to figure 1, which showed no relation between the two measures at all). A simple regression of the average wage firm fixed effect on the number of non-fatal accidents yields an estimated slope coefficient of 0.0034 , which marginally reaches statistical significance (t-value of about 1.6).

Figure 2 about here

Column 1 of table 3 reproduces, for the purpose of comparison, the simple hedonic wage regression using workers from the lowest skill-level only (see section 5.1 above).

Table 3 about here

As it turns out (see column 2, table 3), the point estimate of the risk parameter more then doubles when using $\hat{\psi}$ instead of $y$ directly as the dependent variable in the regression, yielding a point estimate of 0.00067 (with a t-value of more than 2). This result is in line with the story of workers sorting into jobs based on their (partially) unobserved productivity, because the main difference between columns 1 and 2 of table 3 is that variation in $y$ still reflects to a large part variation in unobserved productivity, whereas variation in $\hat{\psi}$ much less so. 


\subsection{Detailed Results}

We present some additional results for different subgroups of the sample, based on both the simple hedonic wage model and on models using the wage firm fixed effect as the dependent variable. The estimates of these additional models are given in table 4 . These additional estimates are consistent with our main result, since in each case the model using the wage firm fixed effect as the dependent variable yields a higher risk compensation than using the observed wage. Panel A of table 4 simply reproduces the result from table 3 discussed above for easy comparison with the other results.

Additionally, these estimates may shed some light on the question of the sorting of workers into firms with different risk compensation and possibly on differences in risk aversion between groups of workers. ${ }^{11}$ Note that, by construction, the estimated firm wage fixed effect $\hat{\psi}_{i j k}$ is the same for all individuals working within a specific firm $j$. It thus must be the case that differences in the estimated risk compensation between subgroups of workers somehow reflect differences in risk compensation between firms. We will be more explicit on this point below when discussing the results.

First, we split the sample by gender (panel B of table 4). The hedonic wage model gives positive point estimates for both men and women, although both are not statistically different from zero. Interestingly, the point estimate of the compensating wage differential is larger for women $(\hat{\delta}=0.00046)$ than for men $(\hat{\delta}=0.00015)$. Using the wage firm fixed effect yields, in both cases, a higher point estimate than using the observed wage $(\hat{\delta}=0.00038$ for men, and $\hat{\delta}=0.0015$ for women), but now in this case both coefficients are statistically different from zero. Still, the estimate for women remains about three times as large as the corresponding estimate for men.

We believe that such a pattern is informative with respect to the underlying sorting of workers into firms with different risk compensation. The results essentially state that women ask a higher risk compensation than men for a given change in the statistical non-fatal accident risk. This result is in line with empirical evidence on differences in risk aversion between men and women (Sunden and Surette, 1998).

Table 4 about here

Second, table 4 (panel C) also shows separate results for smaller (that is, less than 500 employees) and larger (500 or more employees) firms. The simple hedonic wage regression for smaller firms gives us a positive and significant point estimate for risk compensation $(\hat{\delta}=0.00031, \mathrm{t}$-value of about 3.3). For larger firms, we find no effect of accident risk on the firm wage fixed effect (the point estimate is even negative). Moving on to the fixed effects regression, we again get a larger point estimate for the smaller firms $(\hat{\delta}=0.0007$, t-value of about 3.4$)$ and larger firms $(\hat{\delta}=0.00055)$, although for larger firms the estimate remains statistically insignificant.

\footnotetext{
${ }^{11}$ We also split the sample by marital status (i.e. married versus single individuals). We did not find (statistically) different results and we thus do not present these results.
} 
This result states that smaller firms have to pay higher risk compensation for any increase in the risk of non-fatal accident than larger firms do. This difference in risk compensation might reflect underlying differences in the wage setting process between firms of different size. Specifically, one might argue that wages in smaller firms are more likely to reflect competitive wages than in larger firms, where rent sharing is presumably more prevalent than in smaller firms. Another possible explanation for this finding is that workers may perceive working at larger firms per se as more safe (for whatever reason). In statistical terms, in fact, larger firms do not pay any risk compensation at all, which possibly means that larger firms have to guarantee workplace safety anyway because they are presumably under stricter monitoring, whereas smaller firms have more discretion with respect to workplace safety and thus to risk compensation.

\subsection{The Value of a Statistical Injury}

Given an estimate for the compensation for non-fatal accident risk, we can easily compute the value of a statistical injury (i.e. non-fatal accident). Because all our estimates of the risk parameter are based on semi-logarithmic regressions, the estimated risk coefficient corresponds to the relative wage which 1,000 workers are willing to forego in order to prevent one non-fatal accident (and thus is independent of the time period chosen). Thus, multiplying the estimated risk parameter by 1,000 yields the estimated relative value of a statistical injury (VSI):

$$
\mathrm{VSI}=\hat{\delta} \cdot 1,000
$$

Since our risk measure refers to non-fatal accident per year, we will phrase the VSI in terms of average annual earnings (that is, we multiply VSI additionally with the average annual earnings in the corresponding group of workers). Table 5 shows estimates for the value of a statistical injury computed from the different estimation methods discussed above (given in terms of the average annual earnings in the sample). The main estimates are based on the point estimate of the risk variable. Lower and upper bounds on the value of a statistical injury are based on the $95 \%$ confidence interval of each point estimate of the parameter $\delta$.

Table 5 about here

The simple hedonic wage regression actually yields a negative estimate for the value of a statistical injury (per injury per year). Only using the upper bound of the confidence interval yields the expected positive value (although still small).

Stratification of the sample yields a higher value of a statistical injury, the narrower the sample. Focusing on workers in the lowest skill-level only gives an estimate of about 14,000 Swiss francs (the estimate based on the lower bound of the confidence interval though still gives a negative estimate).

Using the wage firm fixed effect finally gives a consistent positive value of a statistical injury (even if we use the lower bound of the corresponding confidence interval). Using the point estimate, we get an estimated value of a statistical injury of about 40,000 Swiss francs 
per non-fatal accident averted per year. This value fits into the range reported by most other studies (see Viscusi and Aldy, 2003, again).

\section{Conclusions}

We provide empirical estimates of the value of a statistical injury for Switzerland for the year 2004, using non-fatal accident risk within industry $\times$ skill-level cells and applying different approaches to identification. Specifically, we try to statistically isolate the firm-specific wage component, to which the theory of compensating wage differentials conceptually applies most directly. Further, we try to mitigate the problem of endogenous worker sorting as far as possible by combining appropriate data and methods.

The empirical method actually makes a huge difference with respect to the estimation of risk compensation. Simple hedonic wage regressions actually yield negative or zero compensation for non-fatal accident risk at the workplace. Moving on to methods we believe are more reliable (i.e. consistent) pushes the risk compensation in the "right" direction (i.e. yielding positive compensation for accident risk). Our preferred estimation method, based on a restricted sample of workers in jobs of lowest skill-level only and using the wage firm fixed effect instead of the observed wage, gives an estimate for the value of a statistical injury of about 40,000 Swiss francs, which is within the range given by both studies from inside and outside the U.S. labor market.

Our analysis, by comparing the magnitude of risk compensation, may also shed some light on the problem of endogenous sorting of workers based on their (unobserved) productivityrelevant characteristics. The more attention we pay to mitigating unobserved productivity differences, the larger the estimates for risk compensation we get. This pattern seems to be consistent with the hypothesis that high-productivity workers select into lower-risk jobs by accepting lower wages. 


\section{References}

Abowd, J. M. and Kramarz, F. (1999). Econometric Analyses of Linked Employer-Employee Data. Labour Economics, 6(1), 53-74.

Ashenfelter, O. (2006). Measuring the Value of a Statistical Life: Problems and Prospects. The Economic Journal, 116, C10-C23.

Baranzini, A. and Ferro-Luzzi, G. (2001). The Economic Value of Risks to Life and Health: Evidence from the Swiss Labour Market. Swiss Journal of Economics and Statistics, 137(2), $149-170$.

DeLeire, T. and Levy, H. (2004). Worker Sorting and the Risk of Death on the Job. Journal of Labor Economics, 22(4), 925-954.

Dreyfus, M. K. and Viscusi, W. K. (1995). Rates of Time Preference and Consumer Valuations of Automobile Safety and Fuel Efficiency. Journal of Law 83 Economics, 38(1), 79-105.

Feinberg, R. M. (1981). Earnings-Risk as a Compensating Differential. Southern Economic Journal, 48(1), 156-163.

Garen, J. (1988). Compensating Wage Differentials and the Endogeneity of Job Riskiness. The Review of Economics and Statistics, 70(1), 9-16.

Hwang, H.-S., Reed, W. R., and Hubbard, C. (1992). Compensating Wage Differentials and Unobserved Productivity. Journal of Political Economy, 100(4), 835-58.

Jenkins, R. R., Owens, N., and Wiggins, L. B. (2001). Valuing Reduced Risks to Children: The Case of Bicycle Safety Helmets. Contemporary Economic Policy, 19(4), 397-408.

Kostiuk, P. F. (1990). Compensating Differentials for Shift Work. Journal of Political Economy, 98(5), 1054-75.

Lalive, R., Ruf, O., and Zweimüller, J. (2006). Compensating Wage Differentials for Employment Risk: Evidence from Linked Firm-Worker Data. Mimeo, University of Zurich.

Mellow, W. and Sider, H. (1983). Accuracy of Response in Labor Market Surveys: Evidence and Implications. Journal of Labor Economics, 1(4), 331-44.

Moretti, E. (2000). Do Wages Compensate for Risk of Unemployment? Parametric and Semiparametric Evidence from Seasonal Jobs. Journal of Risk and Uncertainty, 20(1), 45-66.

Rosen, S. (1986). The Theory of Equalizing Differences. In O. Ashenfelter and R. Layard, editors, Handbook of Labor Economics, chapter 12, pages 641-692. Elsevier.

Shogren, J. F. and Stamland, T. (2002). Skill and the Value of Life. Journal of Political Economy, 110(5), 1168-1197.

Sunden, A. E. and Surette, B. J. (1998). Gender Differences in the Allocation of Assets in Retirement Savings Plans. American Economic Review, 88(2), 207-11.

Viscusi, W. K. (1993). The Value of Risks to Life and Health. Journal of Economic Literature, 31(4), 1912-46.

Viscusi, W. K. and Aldy, J. E. (2003). The Value of a Statistical Life: A Critical Review of Market Estimates throughout the World. Journal of Risk and Uncertainty, 27(1), 5-76. 
Viscusi, W. K. and Hersch, J. (2001). Cigarette Smokers as Job Risk Takers. The Review of Economics and Statistics, 83(2), 269-280.

Viscusi, W. K. and O'Connor, C. J. (1984). Adaptive Responses to Chemical Labeling: Are Workers Bayesian Decision Makers? American Economic Review, 74(5), 942-56.

Wooldridge, J. M. (2002). Econometric Analysis of Cross Section and Panel Data. MIT Press. 


\section{Tables}

Table 1: Descriptive statistics

\begin{tabular}{|c|c|c|c|c|}
\hline & \multicolumn{2}{|c|}{ Skill-level 1} & \multicolumn{2}{|c|}{ Skill-level 1-4 } \\
\hline & Mean & Std. Dev. & Mean & Std. Dev. \\
\hline Monthly wage & 4526.63 & 1069.26 & 6371.88 & 3466.72 \\
\hline Natural logarithm of monthly wage & 8.39 & 0.23 & 8.68 & 0.38 \\
\hline Non fatal accident risk (per 1,000 workers) & 45.40 & 59.13 & 93.01 & 150.42 \\
\hline Age & 40.19 & 11.66 & 40.71 & 11.14 \\
\hline Female & 0.54 & 0.50 & 0.42 & 0.49 \\
\hline Tenure & 7.63 & 8.18 & 9.06 & 9.12 \\
\hline Size of the firm & 2714.94 & 7820.84 & 3108.01 & 7890.73 \\
\hline \multicolumn{5}{|l|}{ Marital status } \\
\hline Single & 0.27 & 0.44 & 0.32 & 0.47 \\
\hline Married & 0.62 & 0.49 & 0.58 & 0.49 \\
\hline Others & 0.11 & 0.31 & 0.10 & 0.30 \\
\hline \multicolumn{5}{|l|}{ Education } \\
\hline University degree & 0.00 & 0.05 & 0.06 & 0.23 \\
\hline College of higher education & 0.00 & 0.05 & 0.05 & 0.21 \\
\hline Higher professional degree & 0.01 & 0.08 & 0.07 & 0.26 \\
\hline Teachers' certificate & 0.00 & 0.04 & 0.00 & 0.07 \\
\hline High School & 0.01 & 0.11 & 0.02 & 0.14 \\
\hline Finished professional education & 0.27 & 0.45 & 0.50 & 0.50 \\
\hline Firm intern professional education & 0.14 & 0.34 & 0.07 & 0.25 \\
\hline Secondary school & 0.48 & 0.50 & 0.18 & 0.38 \\
\hline Other degree & 0.08 & 0.28 & 0.05 & 0.22 \\
\hline \multicolumn{5}{|l|}{ Citizenship } \\
\hline Swiss citizenship & 0.52 & 0.50 & 0.68 & 0.47 \\
\hline Short tem residence authorization & 0.01 & 0.11 & 0.01 & 0.08 \\
\hline Long term residence authorization & 0.08 & 0.28 & 0.05 & 0.23 \\
\hline Permanent recidence permit & 0.29 & 0.45 & 0.17 & 0.37 \\
\hline Cross-border commuter & 0.06 & 0.24 & 0.07 & 0.25 \\
\hline Others & 0.03 & 0.18 & 0.03 & 0.16 \\
\hline \multicolumn{5}{|l|}{ Geographic region } \\
\hline VD, VS, GE & 0.19 & 0.39 & 0.16 & 0.37 \\
\hline $\mathrm{BE}, \mathrm{FR}, \mathrm{SO}, \mathrm{NE}, \mathrm{JU}$ & 0.23 & 0.42 & 0.21 & 0.41 \\
\hline $\mathrm{BS}, \mathrm{BL}, \mathrm{AG}$ & 0.12 & 0.33 & 0.14 & 0.35 \\
\hline $\mathrm{ZH}$ & 0.24 & 0.42 & 0.27 & 0.44 \\
\hline GL, SH, AR, AI, SG, GR, TG & 0.11 & 0.32 & 0.11 & 0.32 \\
\hline LU, UR, SZ, OW, NW, ZG & 0.07 & 0.26 & 0.07 & 0.26 \\
\hline TI & 0.04 & 0.19 & 0.03 & 0.18 \\
\hline Number of Firms & \multirow{2}{*}{\multicolumn{2}{|c|}{$\begin{array}{c}3,533 \\
130,976\end{array}$}} & \multirow{2}{*}{\multicolumn{2}{|c|}{$\begin{array}{c}3,533 \\
468,328\end{array}$}} \\
\hline Number of Observation & & & & \\
\hline
\end{tabular}

Notes: Columns 1 and 2 refer to the subsample of workers in jobs of lowest skill-level, columns 3 and 4 to the full sample of workers. Sources: All variables are taken from the SWSS, except the number of non-fatal accidents. Risk measure gives the number of non-fatal accidents per 1,000 workers per year, within cells over industry $\times$ skill-level. Own calculations, based on SWSS (2004) and SAIF (2004). 


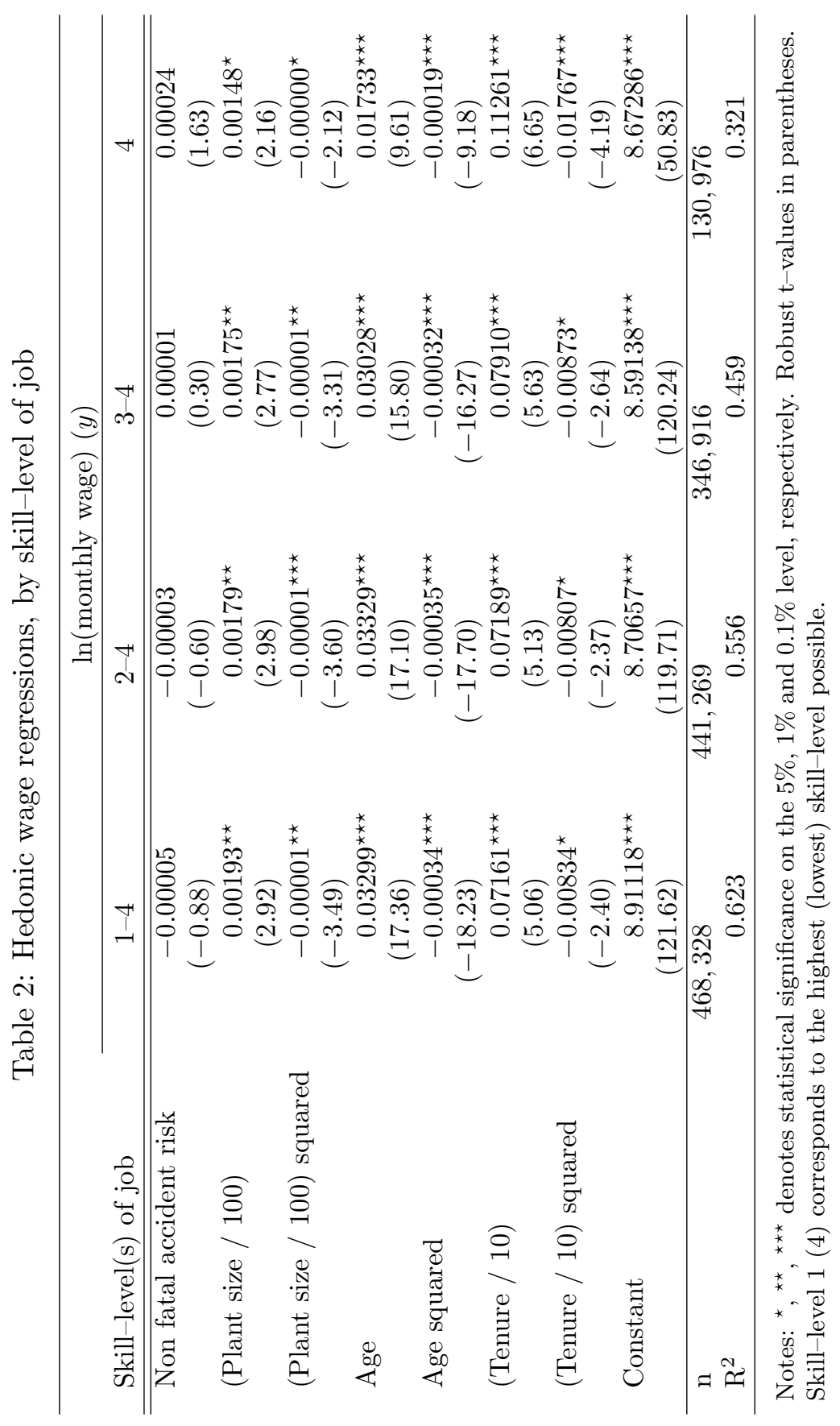


Table 3: Observed wage versus wage firm fixed effect (skill-level 4 only)

\begin{tabular}{lcc}
\hline & \multicolumn{2}{c}{$\ln ($ monthly wage $)$} \\
\cline { 2 - 3 } & Observed wage $(y)$ & Firm fixed effect $(\hat{\psi})$ \\
\hline Non fatal accident risk & 0.00024 & $0.00067^{\star}$ \\
(Plant size / 100) & $(1.63)$ & $(2.41)$ \\
& $0.00148^{\star}$ & $0.00189^{\star}$ \\
(Plant size / 100) squared & $(2.16)$ & $(2.10)$ \\
& $-0.00000^{\star}$ & -0.00000 \\
Age & $(-2.12)$ & $(-1.63)$ \\
& $0.01733^{\star \star \star}$ & $0.00437^{\star}$ \\
Age squared & $(9.61)$ & $-0.00005^{\star}$ \\
& $-0.00019^{\star \star \star}$ & $(-2.68)$ \\
Tenure / 10) & $(-9.18)$ & $0.03799^{\star \star}$ \\
(Tenure / 10) squared & $0.11261^{\star \star \star}$ & $(2.80)$ \\
Constant & $(6.65)$ & $-0.00793^{\star}$ \\
& $-0.01767^{\star \star \star}$ & $(-2.42)$ \\
$\mathrm{n}$ & $(-4.19)$ & -0.08190 \\
$\mathrm{R}^{2}$ & $8.67286^{\star \star \star}$ & $(-1.31)$ \\
\hline
\end{tabular}

Notes: ${ }^{\star},{ }^{\star \star},{ }^{\star \star \star}$ denotes statistical significance on the $5 \%, 1 \%$ and $0.1 \%$ level, respectively. Robust $t$-values in parentheses. Only workers in jobs of lowest skill-level. Own calculations, based on SWSS (2004) and SAIF (2004). 
Table 4: Wage firm fixed effects, detailed results

\begin{tabular}{lcc}
\hline & Log-Wage & Firm fixed effect \\
\hline \hline A. Overall sample & 0.00024 & $0.00067^{\star}$ \\
$\mathrm{n}$ & $(1.63)$ & $(2.41)$ \\
$\mathrm{R}^{2}$ & 130,976 & 130,976 \\
\hline B. By gender & 0.321 & 0.201 \\
Men & & \\
& 0.00015 & $0.00038^{\star \star \star}$ \\
$\mathrm{n}$ & $(0.96)$ & $(3.81)$ \\
$\mathrm{R}^{2}$ & 60,219 & 60,219 \\
Women & 0.304 & 0.192 \\
\cline { 2 - 3 } $\mathrm{n}$ & 0.00046 & $0.00150^{\star}$ \\
$\mathrm{R}^{2}$ & $(1.34)$ & $(2.61)$ \\
\hline C. By size of firm & 70,757 & 70,757 \\
Smaller firms & 0.240 & 0.270 \\
$\mathrm{n}$ & & \\
$\mathrm{R}^{2}$ & $0.00031^{\star \star}$ & $0.00070^{\star \star}$ \\
Larger firms & $(3.29)$ & $(3.36)$ \\
$\mathrm{n}$ & 75,911 & 75,911 \\
$\mathrm{R}^{2}$ & 0.293 & 0.185 \\
\hline
\end{tabular}

Notes: ${ }^{\star},{ }^{\star \star},{ }^{\star \star \star}$ denotes statistical significance on the $5 \%, 1 \%$ and $0.1 \%$ level, respectively. Robust $\mathrm{t}$-values in parentheses. Own calculations, based on SWSS (2004) and SAIF (2004). 


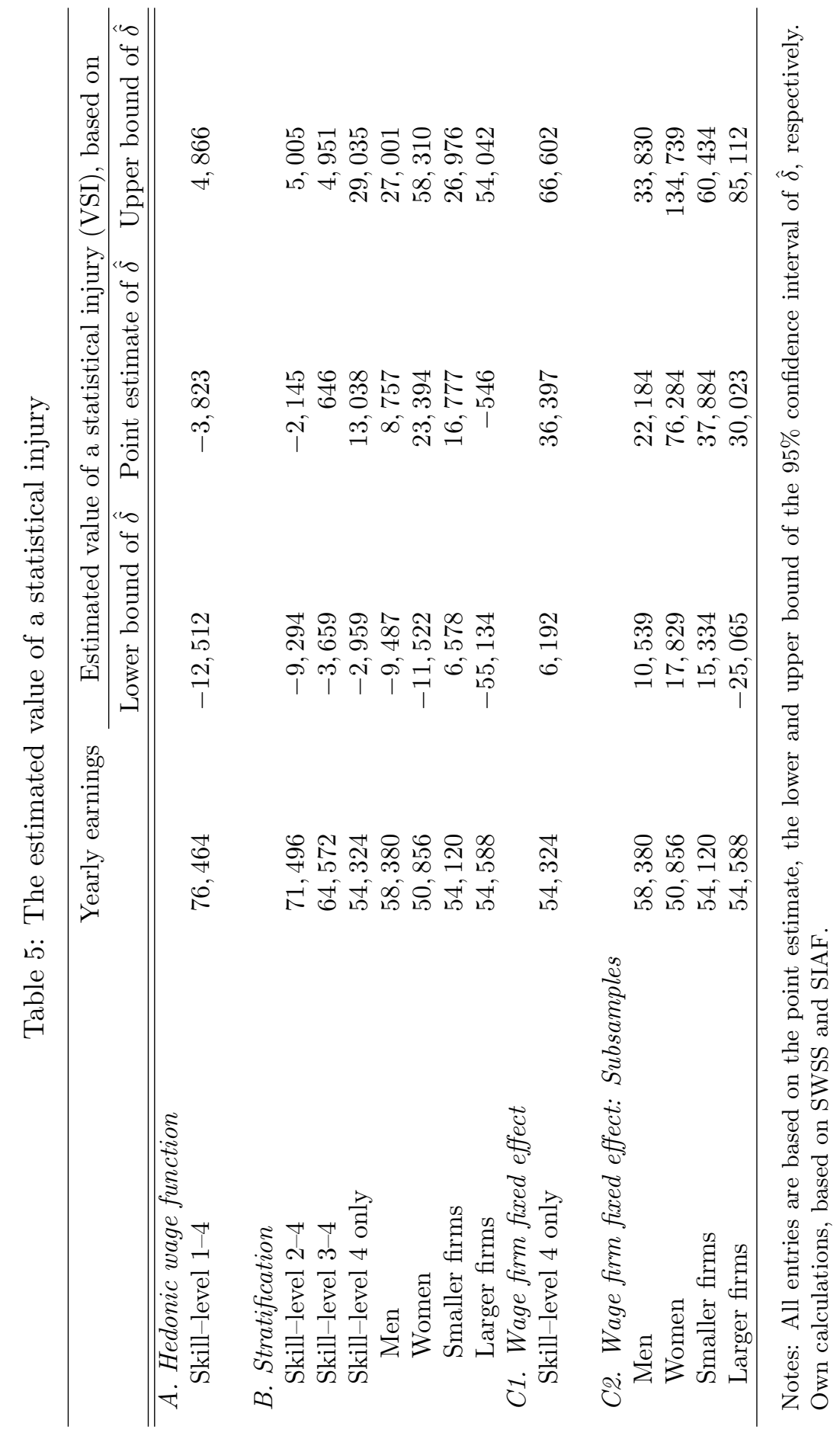




\section{Figures}

Figure 1: Log-Wage versus non-fatal injury risk, by industry

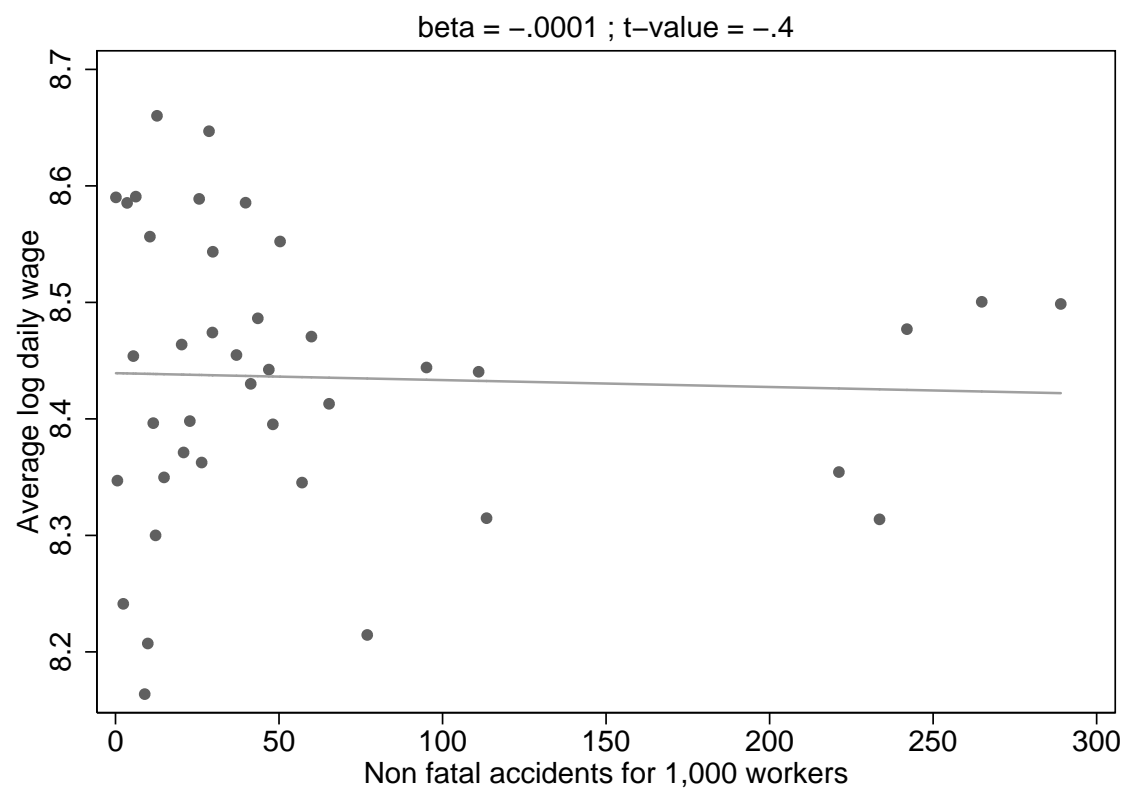

Notes: The y-axis shows the average logarithm of monthly gross earnings and the number of non-fatal accidents per 1,000 workers per year. Workers in lowest job skill-level only. Table A.1 in the chapter appendix shows the corresponding numbers. Own calculations, based on SWSS (2004) and SAIF (2004). 
Figure 2: Firm fixed effect versus non-fatal injury risk, by industry

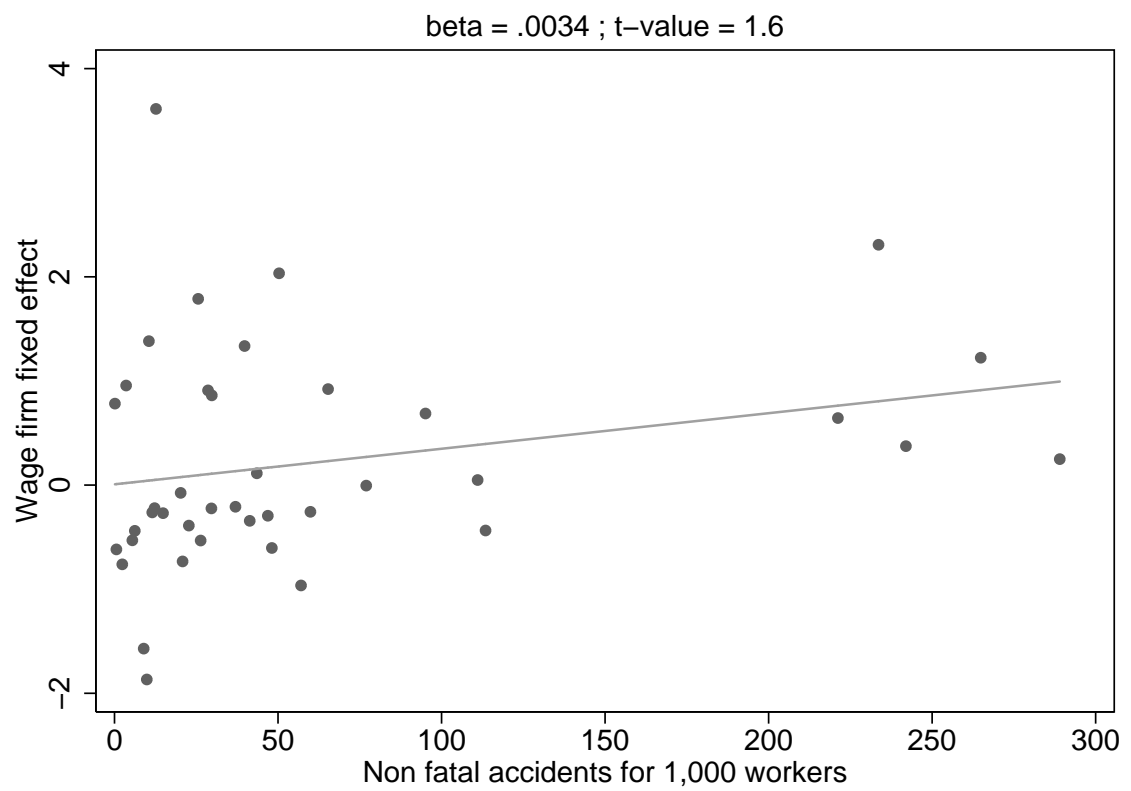

Notes: The $\mathrm{y}$-axis shows the average of the wage firm fixed effect and the $\mathrm{x}$-axis the number of non-fatal accidents per 1,000 workers per year. Workers in lowest job skill-level only. Also see table A.1 in the chapter appendix. Own calculations, based on SWSS (2004) and SAIF (2004). 


\section{A Appendix}

Table A.1: Main variables, by industry (lowest skill-level only)

\begin{tabular}{|c|c|c|c|c|}
\hline Industry & Workers & Earnings & Accidents & FFE \\
\hline Petroleum refining and processing & 4692 & $5,560.13$ & 0.14 & 0.78 \\
\hline Office material production, data processing & 4288 & $4,302.83$ & 0.59 & -0.62 \\
\hline Information technology services & 6237 & $3,933.30$ & 2.39 & -0.76 \\
\hline Shipping & 55 & $5,467.47$ & 3.57 & 0.96 \\
\hline Metal production and processing & 7201 & $4,781.81$ & 5.46 & -0.53 \\
\hline Aviation & 12 & $5,496.25$ & 6.22 & -0.44 \\
\hline Production of leather goods and shoes & 229 & $3,628.01$ & 8.94 & -1.57 \\
\hline Production of clothes and fur goods & 270 & $3,741.27$ & 9.89 & -1.87 \\
\hline Insurance industry & 2086 & $5,300.57$ & 10.53 & 1.38 \\
\hline Production of medical technology & 7421 & $4,523.07$ & 11.55 & -0.26 \\
\hline Retail business & 19118 & $4,090.10$ & 12.26 & -0.22 \\
\hline Tobacco processing & 636 & $5,977.87$ & 12.70 & 3.61 \\
\hline Production of furniture, jewellery, musical intruments & 1743 & $4,329.91$ & 14.86 & -0.27 \\
\hline Machinery/mechanical engineering & 5441 & $4,851.64$ & 20.24 & -0.07 \\
\hline Textiles & 1350 & $4,436.00$ & 20.83 & -0.73 \\
\hline Automobile industry & 1075 & $4,508.15$ & 22.73 & -0.39 \\
\hline Energy- and watersupply & 496 & $5,504.46$ & 25.59 & 1.79 \\
\hline Traffic support & 1502 & $4,360.78$ & 26.35 & -0.53 \\
\hline Credit business & 3059 & $5,833.48$ & 28.60 & 0.91 \\
\hline Paper and carton production & 2153 & $4,917.06$ & 29.64 & -0.22 \\
\hline Credit business and insurance industry & 70 & $5,373.94$ & 29.76 & 0.86 \\
\hline Printing, publishing and distribution industries & 3013 & $4,833.14$ & 36.99 & -0.21 \\
\hline Research and development & 202 & $5,478.94$ & 39.78 & 1.34 \\
\hline Whole sale & 7621 & $4,683.02$ & 41.36 & -0.34 \\
\hline Wood processing & 810 & $4,950.09$ & 43.53 & 0.11 \\
\hline Transportation & 2236 & $4,724.08$ & 46.89 & -0.29 \\
\hline Rubber and plastic production & 2657 & $4,511.65$ & 48.12 & -0.60 \\
\hline Mining & 80 & $5,277.08$ & 50.33 & 2.03 \\
\hline Agriculture & 6756 & $4,310.73$ & 57.05 & -0.96 \\
\hline Mining & 1217 & $4,821.76$ & 59.91 & -0.26 \\
\hline Health and welfare system & 19642 & $4,582.02$ & 65.31 & 0.92 \\
\hline Hotel and restaurant industry & 9676 & $3,743.90$ & 76.98 & -0.01 \\
\hline Real estate & 581 & $4,784.07$ & 95.10 & 0.69 \\
\hline Information transmission & 55 & $4,707.71$ & 111.04 & 0.05 \\
\hline Entertainment & 814 & $4,208.07$ & 113.46 & -0.44 \\
\hline Education & 744 & $4,394.47$ & 221.19 & 0.64 \\
\hline Personal services & 238 & $4,318.43$ & 233.62 & 2.31 \\
\hline Waste management & 95 & $4,953.19$ & 242.00 & 0.37 \\
\hline Lobby, associations, organizations & 512 & $5,067.35$ & 264.88 & 1.22 \\
\hline Construction & 4893 & $4,965.64$ & 289.03 & 0.25 \\
\hline
\end{tabular}

Notes: Table entries show sample averages within industries. Non-fatal accident risk is the number of non-fatal accidents per 1,000 workers. Wage is the average logarithm of gross monthly earnings. Wage firm fixed effect is the average firm fixed effect, as given by equation (6), and is (in the table) standardized to mean 0 and variance 1 . Own calculations, based on SWSS and SIAF. 